\title{
The Characteristics, Structural Level and Construction Path of Collaborative Ecosystem of Innovation and Entrepreneurship Education in Universities
}

\author{
Chuanjuan Zheng ${ }^{\mathrm{a}}$, Mengru Zhang ${ }^{\mathrm{b}}$, Debin Xiao ${ }^{\mathrm{c}}$ \\ School of Zhejiang Tongji Vocational College of Science and Technology, Hangzhou, 311231, \\ China \\ a826272213@qq.com, b53665061@qq.com, c243137624@qq.com
}

\begin{abstract}
Mass entrepreneurship and innovation education in colleges and universities is a systematic project promoted as a whole, which pays attention to the cooperation between different participants and the coupling between top-level design and landing implementation, showing a horizontal and vertical intertwined ecological relationship. Constructing the collaborative ecosystem of innovation and entrepreneurship education in colleges and universities is an important topic to promote the comprehensive reform of colleges and universities, a key way to stimulate the innovation and entrepreneurship vitality of the whole society, and the only way to implement the strategy of "strengthening the country through innovation". The research shows that the collaborative ecosystem of innovation and entrepreneurship education in colleges and universities has the characteristics of the openness of the system boundary, the non-equilibrium of the system state, the nonlinearity of the system dynamics and the fluctuation of the system movement, and includes subject collaboration level, system collaboration level and environmental collaboration level. In terms of the construction path, the research further believes that the construction path of the collaborative ecosystem of innovation and entrepreneurship education in colleges and universities includes three aspects: establishing the system structure, releasing the system power and ensuring the development of the system. Among them, the establishment of the system structure is the premise and the release of the system power is fundamental.
\end{abstract}

Keywords: University Mass Entrepreneurship and Innovation; System; Structural Hierarchy; Construction Path.

\section{Introduction}

In 2015, the general office of the State Council issued the implementation opinions on deepening the reform of innovation and entrepreneurship education in Colleges and universities (hereinafter referred to as the "opinions"), which set off a practice upsurge of innovation and entrepreneurship education in Colleges and universities across the country. During the 13th Five Year Plan period, the number of innovation and entrepreneurship students in Colleges and universities continued to increase, the vitality of innovation and entrepreneurship was high, and achievements emerged. At the same time, academic circles have also achieved fruitful results, especially in the systematic construction of innovation and entrepreneurship in Colleges and universities. There are views on the coordinated development of innovation and entrepreneurship education in Colleges and universities at the level of service strategy[1] and on the construction of ecosystem of innovation and Entrepreneurship Education in Colleges and universities at the level of institutional power[2], The construction view of university innovation and entrepreneurship education community at the main action level [3], the "three innovation integration" view of university innovation and entrepreneurship at the practical training level [4], and the construction view of internal and external collaborative system of university innovation and entrepreneurship education at the talent training level [5]. At present, the academic circles carry out theoretical design on different levels of innovation and entrepreneurship education in Colleges and universities from the perspective of system as a whole, but they have not touched on the collaborative innovation and construction path of innovation and entrepreneurship education in Colleges and universities. As you can see, innovation and entrepreneurship education in Colleges and universities is a systematic project promoted as a whole. 
It pays attention to the cooperation between different participants, the coupling between top-level design and implementation, and presents an intertwined ecological relationship between horizontal and vertical. The collaborative innovation of innovation and entrepreneurship education in Colleges and universities is an important topic to promote the comprehensive reform of colleges and universities, a key way to stimulate the innovation and entrepreneurship vitality of the whole society, and the only way to realize the strategy of "strengthening the country through innovation". It has important theoretical and practical significance for promoting China to enter a new stage of talent training, a new direction of industrial manufacturing and a new field of economic development during the 14th Five Year Plan period.

\section{The Structural Level of Collaborative Innovation in Innovation and Entrepreneurship Education}

As a complex system, the collaborative ecosystem of innovation and entrepreneurship education in Colleges and universities must be gradually developed from a simple system. The process of development is the orderly growth of the system level. Therefore, each level can be regarded as a system in essence. From the perspective of horizontal structure, collaborative ecosystem is the level of subject collaborative system; From the vertical structure, collaborative ecosystem is the level of institutional collaborative system; From the perspective of cross structure, collaborative ecosystem is the level of environmental collaborative system.

The influence and openness of innovation and entrepreneurship education in Colleges and universities are constantly improving, and the scope and degree of subject participation are also expanding, which makes the complexity of the whole collaborative ecosystem more and more significant. From the horizontal structure of the whole system, the subject collaboration level is in an extremely key and important position, including multi-dimensional collaboration among subjects such as government, schools and enterprises. With the steady progress of innovation and entrepreneurship education in Colleges and universities, the degree of subject participation has been continuously expanded, the scope of coordination has been continuously extended, and the governance efficiency has been continuously enhanced. From the perspective of the horizontal category of the whole system, the subject collaboration level occupies the most key and main position, including multi-dimensional collaboration at the subject level such as government, school and enterprise. As the initiator and advocate of innovation and entrepreneurship education, the government defines the implementation path and realization goal of innovation and entrepreneurship education through top-level design. As the main body of direct connection and implementation, colleges and universities formulate the development plan of innovation and entrepreneurship education according to their own conditions, set up theoretical and practical courses of innovation and entrepreneurship education, and create a strong atmosphere and development environment for innovation and entrepreneurship in Colleges and universities. As the carrier and platform of innovation and entrepreneurship education, enterprises, inspired by national policies, provide financial support, practice opportunities and internships for college students, creating extremely favorable external conditions for their innovation and entrepreneurship education.

Institution is the internal regulation and control mode generated among various elements in a complex system [6]. Institutional synergy is an open dynamic mechanism. Therefore, institutional synergy system is the fundamental guarantee to promote the overall virtuous cycle of innovation and entrepreneurship education system. Based on continuously strengthening the cooperation with external subjects, colleges and universities continue to strengthen the top-level system design of innovation and entrepreneurship education, focus on the construction of innovation and entrepreneurship system, focus on the main forces and resources of all parties in the school, and form a multi-level and three-dimensional collaborative network. Formulate development objectives, rules and regulations and implementation measures from the aspects of team construction, organizational structure, personnel allocation, assessment and evaluation. In order to mobilize students' enthusiasm 
and initiative to participate in innovation and entrepreneurship, some colleges and universities carry out system exploration, formulate credit conversion system, implement flexible school system, and formulate innovation and entrepreneurship ability training plans for willing and potential students, Form personalized innovation and entrepreneurship files and second classroom transcripts; In order to fully tap the resources and potential of teachers, colleges and universities turn innovation and entrepreneurship education into an important part of specialty and curriculum construction by improving the management methods of specialty and curriculum construction, refining the relevant systems of practical teaching and management, and linking it with annual assessment indicators, teachers' Professional Title Evaluation and post-employment.

Innovation and entrepreneurship education environment refers to the internal and external environment that promotes the occurrence of innovation and entrepreneurship education, usually including macro environment and innovation and entrepreneurship environment inside and outside the school. Creating a good innovation and entrepreneurship education environment can play a positive role in giving birth to motivation, stimulating vitality, cohesion and improving efficiency. Among them, the macro environment includes the elements that have a potential impact on innovation and entrepreneurship, such as policies and regulations, innovation and entrepreneurship culture, etc. the entrepreneurship environment inside and outside the school refers to the establishment of innovation and entrepreneurship practice platforms inside and outside the school, the development of innovation and entrepreneurship incubation services, the opening of innovation and entrepreneurship courses, the implementation of creativity training, etc. In recent years, in order to promote innovation and entrepreneurship education to a deeper level and create a strong innovation and entrepreneurship atmosphere, local government departments have actively set up platforms, enterprise industry issues, government, industry, University, research and application linkage, schools employ innovation and entrepreneurship mentors, build a collaborative innovation platform between schools, land, schools and enterprises, tap innovation and entrepreneurship curriculum resources, and carry out innovation practice activities, Realize the convergent value demand and value sharing, so as to break the barriers and boundaries between resources.

\section{Construction Path of Collaborative Innovation in Innovation and Entrepreneurship Education}

\subsection{Establishing the Collaborative Ecosystem Structure of Innovation and Entrepreneurship Education in Colleges and Universities}

The establishment of collaborative ecosystem structure of innovation and entrepreneurship education in Colleges and universities is the basic premise. Whether the system structure is complete determines whether its power source is sufficient; Whether the system structure is scientific determines whether the system operates smoothly. Therefore, the establishment of system structure should pay attention to both integrity and scientificity. First of all, we should establish and improve the system of cooperation among the main bodies of innovation and entrepreneurship education in Colleges and universities. The government, universities, enterprises, society and academia are all important participants, promoting the formation of a collaborative ecosystem that encourages participation, cooperation and co governance. The establishment of the system needs to start from the macro, meso and micro levels. At the macro level, we should speed up the introduction of relevant institutional opinions of innovation and entrepreneurship education subjects at the national level, and form a collaborative, effective and scientific top-level design; At the meso level, local governments should closely combine the actual situation of regional colleges and universities and educational environment, and formulate regional policies in accordance with the national system; At the micro level, we should start to establish an effective mechanism for subject coordination, optimize the conditions for system implementation, and ensure policy implementation resources. Secondly, we should establish and improve the system of exchange of innovation and entrepreneurship education resources in Colleges and universities. The formation of open borders is based on the premise of 
resource exchange. Local governments should actively implement the subsidy policy for innovation and entrepreneurship education, fully negotiate with enterprises, universities, society and academia, reach a consensus, and form a virtuous cycle of resource exchange of policy environment - incentive integration - achievement output - market docking - economic development. Thirdly, the construction of a new innovation and entrepreneurship education system should be guided by institutional innovation. It is urgent to revise the talent training plan so that the innovative spirit, entrepreneurial consciousness and innovative and entrepreneurial ability become important indicators of talent training quality; We will implement the annual report system on graduate employment and talent supply and demand in key industries, establish a credit accumulation and conversion system for innovation and entrepreneurship, a temporary training system for full-time teachers in industrial enterprises, and reform the student status management system. Establish a cross training mechanism of cross departments and interdisciplinary majors, a mechanism for the disposal and income distribution of scientific and technological achievements in Colleges and universities, allow the adjustment of academic process, retain student status, suspend school, innovate and start a business, form a number of replicable and popularized institutional achievements, and popularize innovation and entrepreneurship education.

\subsection{Strengthening the Goal Coordination of Innovation and Entrepreneurship Education in Colleges and Universitiesthe Word "Data" is Plural, Not Singular}

The unity of goal collaborative innovation is reflected in the unity of understanding such as common goals, value consensus and win-win interests. Its premise should be based on the formation of clear concept understanding, strong leadership and peer-to-peer goals among various subjects, and innovative positioning of education goals in collaboration. We should actively explore and build a collaborative innovation model of innovation and entrepreneurship education, and enhance the awareness of collaborative innovation. We should start to establish and improve the mechanism of subject coordination and incentive compatibility, create an innovation atmosphere of active participation, and introduce policies in the form of subsidies and rewards to stimulate the vitality of subject participation. For the cooperation between different subjects, different modes should be selected. The education type of cooperation based on goals can form long-term and short-term incentives based on time period, and the education type of cooperation based on demand can form dislocation incentives according to the satisfaction of the needs of different subjects, The education type with education as the direction of cooperation can form value incentive according to different talent levels, and the education type with system as the framework of cooperation can form strong incentive according to the matching degree of mechanism. In addition, we should strengthen the content collaboration of innovation and entrepreneurship education. The accuracy of content collaborative innovation is mainly reflected in the content design, specific arrangement and implementation process of theoretical teaching and practical activities of innovation and entrepreneurship education, as well as the lack of mutual fit between the content supply and the needs of students' personal growth and collaborative practice Supply and demand meet each other accurately. The content design of innovation and entrepreneurship education is unified with the needs of college students.

\subsection{Carrier Synergy of Linkage Innovation and Entrepreneurship Education}

The carrier types of practical innovation and entrepreneurship education in Colleges and universities mainly include different activity forms such as practical teaching, military and political training and social practice. Although the carrier forms are different, they are unified in coordination in terms of educational objectives, methods and value practice. We should further mobilize and integrate all social forces and resources except colleges and universities, form the resource joint force of innovation and entrepreneurship education, and further construct the resource integration mode of innovation and entrepreneurship education in Colleges and universities. "Internet plus" innovation and entrepreneurship education has become a new work idea to be explored in the innovation and 
entrepreneurship education in universities, including richer organizational management information, broader organizational management positions, and more diversified organizational management effects. Its education position has changed from traditional offline to online and offline interactive integration. The construction of virtual practice base has also brought more convenient online resources for innovation and entrepreneurship education, and the education mode has gradually changed from teacher-centered to student-centered.

\section{Acknowledgments}

Fund Project: "Research on the construction of educational community for innovation and entrepreneurship practice in Colleges and universities" (2021010), a scientific research project on human resources and social security in Zhejiang Province in 2021.

\section{References}

[1] L. Zeng, Z.Q. Zhang, Y. N. Liu: University Innovation and Entrepreneurship Education Service "Mass Entrepreneurship and Entrepreneurship" Strategy Needs Coordinated Development, Educational Research, Vol. 38 (2017) No.1, p.70-76+105.

[2] F. Qin, K. Wen: Building an effective innovation and entrepreneurship ecosystem in Colleges and Universities -- institutional arrangement and dynamic mechanism, Scientific research, Vol. 36 (2018) No.4, p. 601-608.

[3] Z. F. Ye: Research on the construction of innovation and entrepreneurship education community in Local Universities Based on the integration of industry and education, Research on higher engineering education, Vol. (2019) No.3, p. 150-155.

[4] S.S. Li, L.F. Li, H.B. Hong, B. Yang: Construction of innovation and entrepreneurship training system in Colleges and universities with "Trinity and integration of three innovations", Educational research of Tsinghua University, Vol. 38(2017) No.2, p. 111-116.

[5] X. F. Zhang, X. R. Shi. Construction of "internal and external cooperation" college innovation and Entrepreneurship Talent Training System, Modern education management, Vol (2018) No.3, p. 47-51.

[6] X. X. Xie, L.L. Zuo, S.Y Liu. Impact of collaborative innovation model of small and medium-sized enterprises on collaborative innovation effect -- dual regulatory effect model of collaborative mechanism and collaborative environment, Science of science and technology management, Vol (2014) No.5, p. 7281 . 